\title{
De Jong Gierveld Loneliness Scale - Short Version: Validation for the Brazilian Context ${ }^{1}$
}

\author{
Gabriel Lins de Holanda Coelho \\ Cardiff University, \\ Cardiff, United Kingdom
}

\author{
Patrícia Nunes da Fonseca \\ Universidade Federal da Paraíba, \\ João Pessoa-PB, Brazil
}

\author{
Valdiney Veloso Gouveia ${ }^{2}$ \\ Universidade Federal da Paraíba, \\ João Pessoa-PB, Brazil
}

\author{
Lukas Jarmo Wolf \\ University of Bath, \\ Bath, United Kingdom
}

\author{
Roosevelt Vilar \\ Massey University, \\ Auckland, New Zealand
}

\begin{abstract}
Individuals who experience a state of loneliness may feel that their needs of belonging are unfulfilled, suffering a state of social deprivation that might affect their well-being. For a better understanding, three studies $(N=939)$ aimed to adapt the short version of the De Jong Gierveld Loneliness Scale to Brazil. In Studies 1 and 2, exploratory and confirmatory analyses corroborated the expected two correlated factors structure: emotional and social. Evidences of convergent validity and factorial invariance between genders were also observed. Study 3 verified the instrument's psychometric properties through Item Response Theory (IRT) and the results showed that the items presented acceptable levels of difficulty, discriminated participants with similar levels of aptitude/ endorsement and indicated that both factors of the measure presented substantial information for a wide range of the latent trait. We conclude that this measure is psychometrically suitable for use in Brazil.
\end{abstract}

Keywords: loneliness, scaling, measurement

\section{Escala de Solidão de De Jong Gierveld - Versão Reduzida: Validação para o Contexto Brasileiro}

\begin{abstract}
Resumo: Indivíduos que vivenciam um estado de solidão podem sentir uma incompletude em suas necessidades de pertença, acarretando um estado de privação social que pode afetar o seu bem-estar. Para melhor entendimento, três estudos $(N=939)$ objetivaram adaptar a versão reduzida da Escala de Solidão de De Jong Gierveld para o Brasil. Nos estudos 1 e 2, análises exploratória e confirmatória corroboraram a estrutura esperada de dois fatores correlacionados: emocional e social. Também se observaram evidências de validade convergente e invariância fatorial entre os gêneros. O estudo 3 avaliou as propriedades psicométricas da medida por meio da Teoria de Resposta ao Item (TRI) e indicou que os itens da escala apresentam níveis de dificuldade satisfatórios, discriminam participantes com níveis próximos de aptidão/endosso e sugerem que os fatores encontrados apresentam informações substanciais para uma larga porção do traço latente. Conclui-se que a medida é psicometricamente adequada para utilização no Brasil.
\end{abstract}

Palavras-chave: solidão, escalas, medidas

\section{Escala de Soledad de De Jong Gierveld - Versión Reducida: Validación al Contexto Brasileño}

\begin{abstract}
Resumen: Los individuos que experimentan un estado de soledad pueden sentir que sus necesidades de pertenencia se encuentran incompletas, sufriendo un estado de privación social que puede afectar su bienestar. Para una mejor comprensión del tema, fueron realizados tres estudios $(N=939)$ que tuvieron como objetivo adaptar la versión reducida de la Escala de Soledad de De Jong Gierveld al contexto brasileño. En los Estudios 1 y 2, los análisis exploratorio y confirmatorio corroboraron la estructura esperada de los factores emocional y social, relacionados entre sí. También fueron observadas pruebas de validez convergente y conservación factorial entre géneros. El Estudio 3 evaluó las propiedades psicométricas de la medida mediante la Teoría de Respuesta al Ítem (TRI) e indicó que los ítems de la escala presentan niveles satisfactorios de dificultad y discriminan participantes con niveles similares de aptitud/aprobación. Además, sugieren que los factores determinados contienen información significativa para una gran parte del rasgo latente. Se concluye que la medida es psicométricamente adecuada para su uso en Brasil.
\end{abstract}

Palabras claves: soledad, escala, pruebas psicométricas

\footnotetext{
'Support: Coordination for the Improvement of Higher Education Personnel (CAPES - Proc. 99999.013718/2013-04) and National Council for Scientific and Technological Development (CNPq - Grant 206803/2014-1), for the Doctoral scholarship provided to the first and fifth authors, respectively.

${ }^{2}$ Correspondence address: Universidade Federal da Paraíba. Departamento de Psicologia. João Pessoa-PB, Brazil. CEP 58.051-900. E-mail: vvgouveia@gmail.com
}

Humans naturally have a strong need to belong, which constitutes a fundamental motivation in their lives. This need to belong and to establish relations with others is so pervasive that it influences people's thoughts, emotions and behaviours, resulting in one of the most important indicators of individual well-being (Baumeister \& Leary, 1995). That 
is, the fulfilment of this need for relationships helps the development of a better quality of life (Jong-Gierveld \& Van Tilburg, 2010). The individuals who experience a state of loneliness may feel that their need to belong is unsatisfied, presenting a state of social deprivation (Baumeister \& Leary, 1995), which has shown to be somewhat common in real life (Hawkley \& Cacioppo, 2010; Pinquart \& Sorensen, 2001).

Jong-Gierveld and Van Tilburg (2010) found that loneliness should be studied as a subjective state, a cognitive assessment of participation and social isolation of the individual, and which should be considered as an expression of negative feelings that can be manifested at any stage of life. Therefore, the opposite of the feeling of loneliness would be to feel incorporated in a group. It is important to point out, however, that a person who is alone is not always in a state of loneliness, and a person who participates in a particular group will not necessarily feel part of it (Hawkley \& Cacioppo, 2010).

Peplau and Perlman (1982) say loneliness is an aversive state experienced when there is a difference between the interpersonal relationships the person desires and what $\mathrm{s} /$ he actually has. This discrepancy shows a deficiency in relationships, both on a quantitative and qualitative level. In particular, Jong-Gierveld and Van Tilburg (2010) claimed that loneliness arises when people feel there is a lack of quality in their relationships, where the individual considers that the number of intimate relations is lower than desirable or allowable.

For a better understanding of the phenomenon, Weiss (1973) made a distinction between two different components of loneliness: (1) Emotional Loneliness, which may develop when there is a lack of a more intimate relationship (e.g., partner, best friend, family). This type of loneliness often occurs, for example, after the divorce or death of a beloved person, and it is characterized by a strong sense of emptiness, abandonment and helplessness; and (2) Social Loneliness, which is related to group interests or networking (e.g., neighbours, cousins, coworkers, and friends). This component can arise when people change their job or the city they live in.

Loneliness is an important construct to understand the well-being of an individual. For instance, loneliness has shown to be meaningfully related to suicide (Goldsmith, Pellmar, Kleinman, \& Bunney, 2002), health risk behaviour (Stickley, Koyanagi, Koposov, Schwab-Stone, \& Ruchkin, 2014), increasing mortality (Luo, Hawkley, Waite, \& Cacioppo, 2012; Steptoe, Shankar, Demakakos, \& Wardle, 2013), cognitive functioning (Hawkley \& Cacioppo, 2010), depression, pain and fatigue (Jaremka et al., 2013), etc. These relationships emphasize the importance of understanding the extent to which people experience loneliness and the necessity to use psychometrically adequate measures to assess the phenomenon.

\section{De Jong Gierveld Loneliness Scale - Short Version}

The De Jong Gierveld Loneliness Scale, composed by 11 items, was developed using the distinction of Weiss (1973) between social and emotional loneliness. The scale can be analysed according to the user's needs. However, the authors suggest that the measure can be analysed either as a single factor or through the emotional and social subscales (JongGierveld \& Kamphuis, 1985).

Jong-Gierveld and Van Tilburg (2006) noted a difficulty when the instrument was used in large surveys. Different researchers pointed out the importance of short instruments as they prevent issues such as boredom and fatigue (Rammstedt \& John, 2007). To solve this problem, the authors created a short version of the De Jong Gierveld Loneliness Scale that still allowed for either testing a single loneliness factor or the corresponding two factors. For that, the authors used six of the 11 original items, three for each of the factors. The short version of the measure is answered on a 5-point Likert scale (1 "Strongly Disagree" to 5 "Strongly Agree"), and it has acceptable psychometric properties, with all the items loadings higher than .40 . In terms of reliability, the short version of the instrument showed Cronbach's alphas $(\alpha)$ between .70 and .76 in different studies, while the alpha of the emotional factor ranged from .67 to .74 , and the alpha of the social factor ranged from .70 to .73 . All these results indicate that the reduced version of the scale showed a clear structure and sufficient reliability.

In order to provide further evidence regarding the psychometric properties of the measure, Jong-Gierveld and Van Tilburg (2010) collected data in other countries. Using samples from France $(n=2.541)$, Germany $(n=2.560)$, Netherlands $(n=1.565)$, Russia $(n=2.804)$, Bulgaria $(n=2.470)$, Georgia $(n=2.266)$, and Japan $(n=1.891)$, with individuals between 17-79 years of age, the results replicated the earlier findings, presenting a framework that supports them. Other validations (e.g., China, Poland, Turkey, Israel) also presented the same structure and psychometric quality (Çavdar, Bağcı, Çorbacı, Sarıtaş, \& Taşdelen-Yayvak, 2015; Grygiel, Humenny, Rebisz, Świtaj, \& Sikorska, 2013; Iecovich, 2013; Leung, Jong Gierveld, \& Lam, 2008).

Considering the results found in recent years and the evidence about the reliability of the short version of the De Jong Gierveld Loneliness Scale, we aimed to assess the psychometric properties of a Brazilian version of this instrument. To do so, we conducted three studies. Study 1 used an exploratory factor analysis to identify the structure of the instrument. Study 2 tested whether this structure could be confirmed in a confirmatory factor analysis, besides its correlations with other constructs. Finally, Study 3 assessed the psychometric properties of the measure from the perspective of Item Response Theory (IRT).

\section{Study 1 - Exploratory Analysis of De Jong Gierveld}

\section{Loneliness Scale (Short Version)}

This first study aimed to examine how the psychometric properties of the short version of the De Jong Gierveld Loneliness Scale would behave in the Brazilian context. To 
test this, we performed a Principal Component analysis and checked the reliability of the instrument.

\section{Method}

\section{Participants}

Participants were 172 individuals with mean age of 23.7 years $(S D=7.77)$, predominantly female $(64.5 \%)$, heterosexual $(80.8 \%)$, single $(84.9 \%)$, middle class $(79.7 \%)$ and Catholic (40.1\%).

\section{Instruments}

De Jong Gierveld Loneliness Scale - Short Version (Jong-Gierveld \& Van Tilburg, 2006). This instrument intends to assess the aspects of social (e.g., "There are many people I can trust completely") and emotional (e.g., "I experience a general sense of emptiness") loneliness of individuals, with three items each, which are answered on a Likert scale, ranging from 1 "Strongly Disagree" to 5 "Strongly Agree". The original version showed Cronbach's alphas $(\alpha)$ between .70 and .76 in different studies, which are considered appropriate in the literature (Kline, 2013).

Demographic questions. These questions were aimed at characterizing the sample, considering age, sex, sexual orientation, marital status, social class, religion and level of education.

We asked two bilingual partners to translate the items from the De Jong Gierveld Loneliness Scale and the instructions, as well as one other partner to perform a back-translation. After that, with the help of 20 high school students equally distributed in terms of gender, we determined the level of understanding, clarity and ease of answering. We asked them to provide feedback on their impressions of this pilot version of the scale, which we used to improve the structure and wording of the items.

\section{Procedure}

Data collection. This study was conducted online. More specifically, the questionnaire was prepared and administered on the Google Docs platform, and the questionnaire was shared on social networks. Participants were asked to complete the De Jong Gierveld Loneliness Scale - Short Version and demographic questions. The average time to complete the survey was five minutes.

Data analysis. The $R$ statistical program ( $R$ Development Core Team, 2015) was used. Firstly, by means of Student's $\mathrm{t}$ test, we observed the discriminative power of the items. Then, the criteria of Kaiser-Meyer-Olkim (KMO) and Bartlett's Test of Sphericity were applied, using the statistical packages Psych and Corpcor (Revelle, 2013; Schäfer et al., 2013). After that, we determined the number of components that would be extracted using the packages nFactors and
Psych (Raiche, Walls, Magis, Riopel, \& Blais, 2013). Finally, a Principal Component Analysis and a reliability analysis were performed. For these analyses, we used the psych and ltm packages (Rizopoulos, 2015).

\section{Ethical Consideration}

The following studies received approval from the Committee for Ethics and Research with Human Beings, of the Federal University of Paraíba (CAAE 30265814.6.0000.5188). All the ethical principles were respected, guaranteeing the anonymous and voluntary participation of the respondents, and the possibility to decline the completion of the survey.

\section{Results}

Initially, we tested the discriminative power of the six items of the Loneliness Scale. This analysis served to determine if items were able to distinguish participants whose answers were close to the median. We obtained the median across the summed scale items and divided the data into two groups, one below and one above the median. Then, $t$ tests were performed to check whether the two groups differed in their item scores. All the responses were statistically different for participants with close ranges $(p<.001)$. The full table with the discriminative power of items can be requested from the authors.

Before proceeding to the Principal Component analysis, it was necessary to check the factorability of the item correlation matrix. Thus, we examined the KMO criteria, which must be greater than .60 , and Bartlett's sphericity test, which must be significant (Tabachnick \& Fidell, 2013). The results enabled us to perform the Principal Component Analysis $\left[\mathrm{KMO}=.74\right.$; Bartlett's Test of Sphericity, $\chi^{2}(15)=$ 288.06, $\mathrm{p}<.001]$.

To identify the number of components to be taken from the scale, we observed five different criteria: (1) Kaiser, which considers eigenvalues higher than 1 as different factors; (2) Cattell (Scree Plot), a graphical and subjective demonstration of the eigenvalues, which considers values prior to the "elbow" of the figure as factors; (3) Horn (parallel analysis), which verifies the superiority of the eigenvalues in comparison to simulated results; (4) Optimal Coordinates, which acts similarly to Horn's criteria; and (5) Acceleration Factor, which checks where the curve shows a drastic change, thus finding the number of factors (Raiche et al., 2013). In four of the five criteria, we found a structure with two components, being consistent with the original structure (Jong-Gierveld \& Van Tilburg, 2006). Therefore, we conducted a Principal Component analysis, considering the two-component structure using a Varimax rotation. We considered items with factor loadings above $|.50|$ and eliminated items that loaded on more than one factor. The results can be seen in Table 1. 
Table 1

Items loadings of the De Jong Gierveld Loneliness Scale

\begin{tabular}{|c|c|c|c|}
\hline \multirow{2}{*}{ Item } & \multicolumn{2}{|c|}{ Component } & \multirow{2}{*}{$\mathrm{h}^{2}$} \\
\hline & $I$ & II & \\
\hline $\begin{array}{l}\text { 1. I experience a general sense of } \\
\text { emptiness }\end{array}$ & $.83 *$ & -.04 & .69 \\
\hline 5. I often feel rejected & $.76^{*}$ & -.20 & .62 \\
\hline 3. I miss having people around & $.70^{*}$ & -.21 & .53 \\
\hline $\begin{array}{l}\text { 2. There are plenty of people I can rely } \\
\text { on when I have problems (R) }\end{array}$ & -.17 & $.89 *$ & .82 \\
\hline $\begin{array}{l}\text { 4. There are many people I can trust } \\
\text { completely }(\mathrm{R})\end{array}$ & -.10 & $.89 *$ & .80 \\
\hline $\begin{array}{l}\text { 6. There are enough people I feel close } \\
\text { to }(\mathrm{R})\end{array}$ & -.49 & $.54^{*}$ & .53 \\
\hline Number of Items & 3 & 3 & \\
\hline Eigenvalues (Rotate) & 2.03 & 1.95 & \\
\hline$\%$ of Variance (Rotate) & 34 & 33 & \\
\hline McDonald's Omega $(\omega)$ & .79 & .87 & \\
\hline Cronbach's alpha $(\alpha)$ & .69 & .76 & \\
\hline
\end{tabular}

Note. *Satisfactory loadings; $(\mathrm{R})=$ Reversed items.

The data showed that none of the items loaded in more than one factor and that all of them presented factor loadings of .50 or superior. Component I was composed of three items and had a rotated eigenvalue of 2.03 , explaining $34 \%$ of the total variance. This component reflected the Emotional dimension with a McDonald's Omega $(\omega)$ of .79, Cronbach's alpha $(\alpha)$ of .69 , and revealed an inter-item correlation (i.e., homogeneity) of .43 , ranging from .38 to .50 . Component II represented the Social dimension of the scale, which was also composed of three items and showed a rotated eigenvalue of 1.95 , accounting for $33 \%$ of the total variance. The McDonald's Omega $(\omega)$ of this subscale was .87 , while the Cronbach's alpha $(\alpha)$ was .76. The inter-item correlation was .51, ranging from .38 to .68 . Results showed a McDonald's Omega ( $\omega)$ of .83 and a Cronbach's alpha $(\alpha)$ of .77 across all the scale items.

\section{Discussion}

The first study aimed to assess the appropriateness of the short version of the De Jong Gierveld Loneliness Scale in Brazil by examining its factorial structure and reliability. We obtained a factorial structure similar to the original study, i.e. two components with three items each. Furthermore, the components revealed reliability levels above the minimum considered in the literature. These results are promising and provide support for the usefulness of the Brazilian version. We wished to obtain more evidence for the robustness of these findings though. Hence, we tested whether we can corroborate these findings in a confirmatory factor analysis.

\section{Study 2 - Confirmatory Analysis of De Jong Gierveld Loneliness Scale (Short Version)}

The second study aimed to corroborate the structure of the short version of the De Jong Gierveld Loneliness Scale using a confirmatory factor analysis. In addition, we performed an MGCFA to test if men and women answer the instrument in the same way. Maio and Esses (2001) suggested that men may learn to avoid their emotions because it can be an indicator of weakness for them. This detachment of emotions might lead men to experience lower states of loneliness. Similarly, a meta-analysis performed by Pinquart and Sorensen (2001) has shown that women tend to experience significantly higher levels of loneliness. In addition to these findings, Jong-Gierveld and Van Tilburg (2010) indicated that women experience more intense emotional loneliness, while men tend to experience higher social loneliness. Hence, to examine if gender differences affect the validity of the instrument, we performed an MGCFA. Finally, we examined the instrument's convergent validity by examining its relationship with another loneliness measure and an instrument of positivity.

\section{Method}

\section{Participants}

This study recruited 220 students with a mean age of 21.9 $(S D=5.64)$, predominantly female $(59.5 \%)$, heterosexual (93.6\%), single (81 8\%), from the middle class $(80.5 \%)$ and Catholic (46.4\%).

\section{Instruments}

For the second study, besides the De Jong Gierveld Loneliness Scale and a demographic questionnaire, we used a measure of positivity and another instrument of loneliness for convergent validity purposes. They are described below.

Positivity scale. This instrument was developed by Caprara, Steca, Alessandri, Abela, and McWhinnie (2010), and adapted to the Brazilian context by Souza, Araújo, Gouveia, Coelho, and Gouveia (2014). It assesses the individuals' level of positivity, which is an important aspect of well-being. This scale consists of eight items (e.g., "I generally feel confident in myself"; "I feel I have many things to be proud of"), which are answered on a 7-point scale, from 1 "Strongly Disagree" to 5 "Strongly Agree". In the Brazilian adaptation, this instrument showed a Cronbach's alpha $(\alpha)$ of .85 .

UCLA Loneliness Scale. We used a short version of the UCLA measure of loneliness, developed by Hughes, Waite, Hawkley and Cacioppo (2004), consisting of three items (e.g., "How often do you feel left out?") on a 5-point scale, ranging from 1 "Never" to 5 "Always". This instrument aims to examine people's own perception of their social isolation. In the original study, this scale showed a Cronbach's alpha $(\alpha)$ of .72. 


\section{Procedure}

Data collection. We contacted various undergraduate courses at a public university in João Pessoa - PB, Brazil. After prior authorization, the students were asked to complete the questionnaires individually. The average participation time was ten minutes.

Data analysis. The confirmatory factor analysis was conducted using Mplus. To perform the confirmatory factor analysis (CFA), the Robust Maximum Likelihood (Robust ML) estimator was used. This estimator is robust to the nonnormality of the data and it is recommended for scales with at least five points of answer (Rhemtulla, Brosseau-Liard, \& Savalei, 2012), such as the De Jong Gierveld Loneliness Scale. Thus, to evaluate the model's goodness-of-fit, the following indices were considered: $\mathrm{S} \chi^{2}$ (chi-square) / df (degrees of freedom) using the Satorra-Bentler Scaled ChiSquare, Comparative Fit Index (CFI), Standardized Root Mean Square Residual (SRMR), and Root Mean Square Error Approximation (RMSEA). Based on the literature, we used the following cut-off criteria to evaluate the model fit of the De Jong Gierveld Loneliness Scale: $\mathrm{S} \chi^{2}$ must be nonsignificant, the CFI value must be higher than .90 or close to .95 , the SRMR value must be .08 or less, and the RMSEA value must be lower than .06 , while values lower than .10 are deemed acceptable for small samples and small degrees of freedom (Brown \& Moore, 2013; Hair, Black, Babin, \& Anderson, 2015; Kenny, Kaniskan, \& McCoach, 2014; Tabachnick \& Fidell, 2013).

We also performed a Multi-group Confirmatory Factor Analysis (MGFCA), a robust method to test the measurement equivalence between different groups. In this analysis, we tested the sex invariance. The following models were considered (Damásio, 2013; Milfont \& Fischer, 2010): (1) Configural invariance, which indicates if the structure is invariant across groups; (2) Metric invariance, which checks if the groups answer the items in the same way; and (3) Scalar invariance, which indicates if the observed scores are related to latent scores. Even though Milfont and Fischer (2010) point out that these three levels are enough to reflect the invariance of a measure, there are additional levels that can be considered: (4) Error variance invariance, used to check if the items present the same level of measurement error; (5) Factor variance, which checks if the range of scores in a factor does not vary; and (6) Factor mean, used to indicate if the groups differ in the underlying constructs. In this analysis, we considered the $\Delta \mathrm{S} \chi^{2}$, which needs to be nonsignificant (Damásio, 2013), and the $\triangle \mathrm{SRMR}$, which has to lower than .01 (Chen, 2007). If satisfied, the parameters indicate invariance across groups.

\section{Results}

This second study sought to confirm the previous structure. In addition, we tested an alternative model loading all the items in a single factor. The one-factor model showed no acceptable fit $\chi^{2}(9)=31.26$, CFI $=.86$, TLI $=.77$, RMSEA $=.11(.067-.148)$. On the other hand, the results revealed that the two-factor model was psychometrically satisfactory: $\mathrm{S} \chi^{2}(8)=18.65, \mathrm{p}=.017, \mathrm{CFI}=.93, \mathrm{SRMR}=.04$, $\mathrm{RMSEA}=.07(90 \% \mathrm{CI}=.031-.124)$. All the factorial weights $(\lambda$, lambdas) loaded from .50 (Item 05$)$ to .71 (Item 03$)(M=.60)$ on the factors, and were statistically different from zero $(\lambda \neq 0, \mathrm{z}>1.96, p<.001)$.

Next, we performed an MGCFA to test the invariance of the instrument across sex. This analysis yielded the parameters $\Delta \chi^{2}$ and $\Delta$ SRMR, which can be seen in Table 2. Given that $\Delta \chi^{2}$ was not significant (Damásio, 2013), and $\triangle$ SRMR did not exceed .01 (Chen, 2007), these parameters indicated invariance across both genders. Additionally to these findings, we checked the sex differences in emotional and social factors. The findings suggest no significant differences for both emotional $[t(207)=-1.82, p=.07$; Cohen's $d=.26]$ and social $[t(207)=-.84, p=.39$; Cohen's $d=.12]$ factors.

Table 2

Factorial invariance of the instrument regarding gender

\begin{tabular}{lcccc}
\hline Models & \multicolumn{1}{c}{$\chi^{2}(\mathrm{gl})$} & $\Delta \chi^{2}(\mathrm{gl})$ & SRMR & $\Delta$ SRMR \\
\hline $\begin{array}{l}\text { Configural } \\
\text { invariance }\end{array}$ & $23.67(16)$ & - & .056 & - \\
Metric invariance & $25.10(20)$ & $1.43(4)$ & .058 & .002 \\
$\begin{array}{l}\text { Scalar invariance } \\
\text { Error variance }\end{array}$ & $29.60(24)$ & $4.50(4)$ & .066 & .008 \\
$\begin{array}{l}\text { invariance } \\
\text { Factor variance }\end{array}$ & $37.68(30)$ & $8.08(6)$ & .072 & .006 \\
Factor mean & $42.70(32)$ & $1.02(2)$ & .073 & .001 \\
\hline
\end{tabular}

In order to provide evidence of the convergent validity of the scale, we performed correlations with the Positivity Scale $(\alpha=.66)$ and a short version of the UCLA $(\alpha=.67)$. As expected, the scale of positivity correlated negatively with the emotional $(r=-.34, p<.001)$ and social $(r=-.34$, $p<.001$ ) factors. Also consistent with our expectations, the reduced version of the UCLA showed positive correlations with both factors: emotional $(r=.64, p<.001)$ and social $(r=.42, p<.001)$.

\section{Discussion}

After the exploratory factor analysis in the first study, we aimed to provide stronger psychometric evidences by using confirmatory factor analyses (CFA) and multigroup CFA. We found that the proposed two-factor model presents satisfactory model fit and was invariant to gender. Finally, we obtained additional evidence for the instrument's convergent validity. The correlation was negative for the positivity scale and positive for the UCLA instrument, as expected. Therefore, we can be confident 
about the psychometric properties of the scale and about the possibility of its use in Brazil.

\section{Study 3 - Analysis of De Jong Gierveld Loneliness Scale (Short Version) in Item Response Theory (IRT)}

The third study used an IRT approach that is based on the Latent Trait Theory (Embretson \& Reise, 2013). This approach aimed to verify the items' level of difficulty (i.e., a parameter that indicates how likely the item is to be correctly answered or endorsed), their discrimination (i.e., a parameter that indicates the ability of the item to discriminate participants with close levels of agreement), and the factors' power of information (i.e., if the factors present wide information in the evaluated latent trait).

\section{Method}

\section{Participants}

We recruited 457 participants with a mean age of 24.8 $(S D=7.03)$, predominantly female $(60.3 \%)$, heterosexual $(91.9 \%)$, single $(80.7 \%)$, Catholic $(53.8 \%)$ and from the middle socioeconomic class (83.8\%).

\section{Instrument}

Only the loneliness measure and a demographic questionnaire were used in this study. The average time to complete the survey was five minutes.

\section{Procedure}

Data collection. As in the previous two studies, participants were recruited via social media (online) and in universities (face-to-face).

Data analysis. The data was submitted to an IRT Graded Response analysis - GRM (Samejima, 1968), using the ltm and mirt packages in the software R (Chalmers, Pritikin, Robitzsch, \& Zoltak, 2015; Rizopoulos, 2015). In this analysis, we estimated the GRM parameters for all items in order to assess their difficulty and discrimination, in addition to the factors' power of information.

\section{Results}

First, we assessed the difficulty and the discrimination parameters of the items. As can be seen in Table 3, the difficulty parameters ranged from -1.54 to 2.77 for the emotional factor, and from -1.66 to 3.93 for the social factor, representing a large portion of the latent trait. The discrimination index (a) presented satisfactory values, ranging from 1.76 to 1.89 for the emotional factor, and from 1.03 to 5.64 for the social factor (Baker, 2001).
Moreover, we examined the test information curve, which indicates how much information the measure contains about the latent trait (Andrade, Laros, \& Gouveia, 2010). This curve graphically represents at which levels of $\theta$ (levels of participants' ability or agreement) the test is informative. The three items of the emotional factor provided a total of $99.19 \%$ of the information on a range from -4 to 4 , while the three items of the social factor provided $92.01 \%$ of the information in a range from -2 to 2 , with a higher power of information in a smaller radius of the latent trait. Both factors had a distribution within the normal range (near the point 0 ). The total test information for both factors can be seen in Figure 1 .

Table 3

Graded Response Model: Discrimination and Difficulty

\begin{tabular}{|c|c|c|c|c|c|}
\hline & $\mathrm{a}$ & $\beta_{1}$ & $\beta_{2}$ & $\beta_{3}$ & $\beta_{4}$ \\
\hline \multicolumn{6}{|c|}{ Emotional Factor } \\
\hline Item 1 & 1.89 & -1.45 & -.23 & .39 & 1.75 \\
\hline Item 3 & 1.85 & -1.54 & .28 & .66 & 2.05 \\
\hline Item 5 & 1.76 & -.74 & .57 & 1.70 & 2.77 \\
\hline \multicolumn{6}{|c|}{ Social Factor } \\
\hline Item 2 & 5.64 & -1.11 & .07 & .54 & 1.61 \\
\hline Item 4 & 1.96 & -1.66 & -.47 & .15 & 1.39 \\
\hline Item 6 & 1.03 & -1.43 & .86 & 1.99 & 3.93 \\
\hline
\end{tabular}
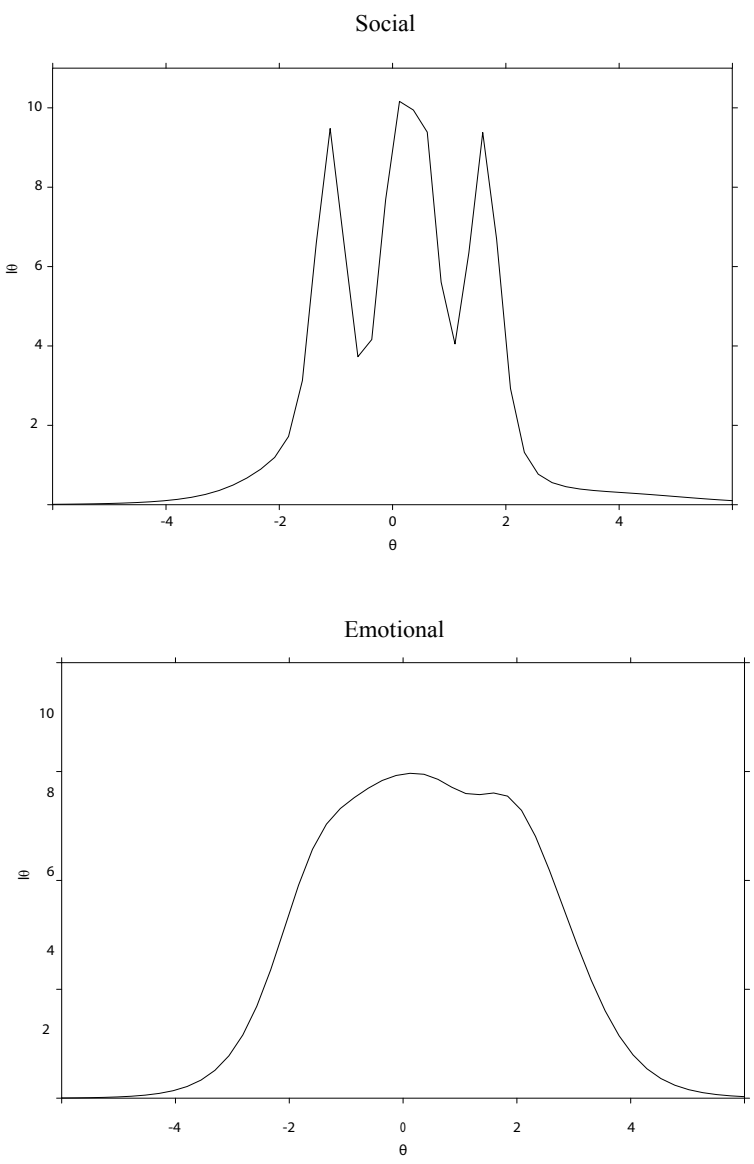

Figure 1. Total test information for Emotional and Social factors. 


\section{Discussion}

This study aimed to present the psychometric properties of De Jong Gierveld Loneliness Scale from the perspective of IRT. We used this approach to assess the level of difficulty and discrimination of the items, and the power of information presented by the factors. As has been demonstrated, all instrument items showed high discrimination rates and varied levels of difficulty, covering different levels of agreement (Baker, 2001). The test information curve also revealed that the factors were able to offer information of participants with different levels of agreement, representing a wide coverage of the latent trait for both factors. In sum, these findings suggest that the De Jong Gierveld Loneliness Scale features items with acceptable levels of difficulty to discriminate participants and presents broad power of information.

\section{Conclusions}

People's relationships form a fundamental aspect in the development of individuals, acting as one of the most important indicators of personal well-being (Jong-Gierveld \& Van Tilburg, 2006). The lack of these relationships in everyday life can lead the individuals to experience states of loneliness, which can affect their happiness and behaviours (Baumeister \& Leary, 1995). The relevance of studying loneliness is manifested in such detrimental consequences as suicide, alcoholism or depression (Goldsmith et al., 2002; Jaremka et al., 2013; Stickley et al., 2014). The aim of this research was to adapt the De Jong Gierveld Loneliness Scale to the Brazilian context, assessing its reliability, factorial structure, and convergent validity. As in the original study conducted by Jong-Gierveld and Van Tilburg (2006), the present research revealed a twofactor solution, where the items were equally distributed between the emotional and social factors, as expected. The instrument also revealed acceptable reliability levels, through McDonald's Omega $(\omega=.83)$ and Cronbach's alpha $(\alpha=.77)($ Kline, 2013).

First, we performed a Principal Component analysis to examine how the structure would behave in the Brazilian context, finding the same two-factors distribution, all six items being equally distributed among them. Given that this is a first step to test an instrument's structure, we decided to conduct a second study with a more robust statistical approach, in order to confirm the results. The indicators of the Confirmatory Factor analysis showed acceptable fit indices for the factorial structure (Hair et al., 2015; Tabachnick \& Fidell, 2013). We also performed a Multi-group Confirmatory Factor analysis to provide more evidence about the quality of the instrument. This analysis reveals if the measure presents equivalent configuration and parameters among different groups (Damásio, 2013). In this situation, the results showed that men and women answered the instrument in the same way across all the models considered, showing its invariance across the participants' sex.
Moreover, loneliness was correlated with different constructs, such as positivity and another loneliness instrument, in order to provide evidences of convergent validity to the measure. The results showed a negative and significant correlation with the positivity scale, which seems reasonable, as loneliness is an important construct to understand well-being, with different research showing its relationship with problems like depression (Jaremka et al., 2013) and suicide (Goldsmith et al., 2002). Also as expected, the scale showed positive and significant results in relation to the other loneliness measure.

After providing more evidence concerning the psychometric properties of the measure, we conducted an IRT analysis. The results provided new information about the instrument, showing that its items present acceptable levels of difficulty and are able to discriminate participants with different levels of agreement. Besides, both factors provided enough information about loneliness, showing its precision of measurement.

Despite the psychometric evidence found, it is necessary to highlight the potential limitations of the study. The main limitation was the use of a convenience sample (nonprobability), which compromises the generalizability of the results, potentially not representing the Brazilian population. Therefore, we consider it important to conduct more research on loneliness and its relevance to people's lives in Brazil. Importantly, the present research provided strong support for the quality and usability of the De Jong Gierveld Loneliness Scale in Brazil. We trust that the use of this scale can bring benefits to the research on well-being, as well as to research on interpersonal relationships. It is important to emphasize, however, that the main objective of these studies is to provide psychometric evidence for the instrument.

Future studies may provide further evidence to understand the relationship between this construct and other variables with individual levels of difference, such as people's value priorities. For instance, it would be interesting to examine whether people who are more likely to focus on personal values, e.g. emotion, pleasure (Gouveia, Milfont, \& Guerra, 2014) present high scores in loneliness. Future studies could also focus on cultural differences in loneliness, observing how different societies experience this state, regarding their economic circumstances, traditions and behaviours.

\section{References}

Andrade, J. M., Laros, J. A., \& Gouveia, V. V. (2010). O uso da teoria de resposta ao item em avaliações educacionais: Diretrizes para pesquisadores. Avaliação Psicológica, 9(3), 421-435.

Baker, F. B. (2001). The basics of item response theory (2nd ed.). Retrieved from http://files.eric.ed.gov/fulltext/ ED458219.pdf 
Baumeister, R. F., \& Leary, M. R. (1995). The need to belong: Desire for interpersonal attachments as a fundamental human motivation. Psychological Bulletin, 117(3), 497529. doi:10.1037/0033-2909.117.3.497

Brown, T. A., \& Moore, M. T. (2013). Confirmatory factor analysis. In R. H. Hoyle, Handbook of structural equation modeling (pp. 361-379). New York, NY: Guilford Press.

Caprara, G. V., Steca, P., Alessandri, G., Abela, J. R., \& McWhinnie, C. M. (2010). Positive orientation: Explorations on what is common to life satisfaction, self-esteem, and optimism. Epidemiology and Psychiatric Sciences, 19(1), 63-71. doi:10.1017/ S1121189X00001615

Çavdar, D., Bağcı, V., Çorbacı, E. C., Sarıtaş, S., \& TaşdelenYayvak, M. K. (2015). Adaptation of De Jong Gierveld Loneliness Scale into Turkish. International Journal of Humanities and Social Science, 5(9), 84-92. Retrieved from http://www.ijhssnet.com/journals/Vol_5_No_9 September_2015/8.pdf

Chalmers, P., Pritikin, J., Robitzsch, A., \& Zoltak, M. (2015). MIRT: Multidimensional Item Response Theory (Version 1.9). Retrieved from http://cran.r-project.org/web/ packages/mirt/index.html

Chen,F.F.(2007). Sensitivityofgoodnessoffitindexestolack of measurement invariance. Structural Equation Modeling, 14(3), 464-504. doi:10.1080/10705510701301834

Damásio, B. F. (2013). Contribuições da Análise Fatorial Confirmatória Multigrupo (AFCMG) na avaliação de invariância de instrumentos psicométricos. Psico-USF, 18(2), 211-220. doi:10.1590/S1413-82712013000200005

Embretson, S. E., \& Reise, S. P. (2013). Item Response Theory for psychological. Hove, United Kingdom: Psychology Press.

Goldsmith, S. K., Pellmar, T. C., Kleinman, A. M., \& Bunney, W. E. (2002). Reducing suicide: A national imperative. Washington, DC: National Academy Press.

Gouveia, V. V., Milfont, T. L., \& Guerra, V. M. (2014). Functional theory of human values: Testing its content and structure hypotheses. Personality and Individual Differences, 60, 41-47. doi:10.1016/j.paid.2013.12.012

Grygiel, P., Humenny, G., Rebisz, S., Świtaj, P., \& Sikorska, J. (2013). Validating the Polish adaptation of the 11item De Jong Gierveld Loneliness Scale. European Journal of Psychological Assessment, 29(2), 129-139. doi:10.1027/1015-5759/a000130

Hair, J. F., Jr., Black, W. C., Babin, B. J., \& Anderson, R. E. (2015). Multivariate data analysis (7th ed.). Upper Saddle River, NJ: Prentice Hall.
Hawkley, L. C., \& Cacioppo, J. T. (2010). Loneliness matters: A theoretical and empirical review of consequences and mechanisms. Annals of Behavioral Medicine: A Publication of the Society of Behavioral Medicine, 40(2), 218-227. doi:10.1007/s12160-010-9210-8

Hughes, M. E., Waite, L. J., Hawkley, L. C., \& Cacioppo, J. T. (2004). A short scale for measuring loneliness in large surveys: Results from two populationbased studies. Research on Aging, 26(6), 655-672. doi: $10.1177 / 0164027504268574$

Iecovich, E. (2013). Psychometric properties of the Hebrew version of the De Jong Gierveld Loneliness Scale. Educational Gerontology, 39(1), 12-27. http://doi.org/10 $.1080 / 03601277.2012 .660860$

Kenny, D. A., Kaniskan, B., \& McCoach, D. B. (2014). The Performance of RMSEA in Models With Small Degrees of Freedom. Sociological Methods \& Research, 44(3), 486-507. https://doi.org/10.1177/0049124114543236

Kline, P. (2013). Handbook of psychological testing. New York, NY: Routledge.

Jaremka, L. M., Fagundes, C. P., Glaser, R., Bennett, J. M., Malarkey, W. B., \& Kiecolt-Glaser, J. K. (2013). Loneliness predicts pain, depression, and fatigue: Understanding the role of immune dysregulation. Psychoneuroendocrinology, 38(8), 1310-1317. doi:10.1016/j.psyneuen.2012.11.016

Jong-Gierveld, J., \& Kamphuis, F. (1985). The development of a Rasch-type loneliness scale. Applied Psychological Measurement, 9(3), 289-299. doi:10.1177/014662168500900307

Jong-Gierveld, J., \& Van Tilburg, T. (2006). A 6-Item Scale for Overall, Emotional, and Social Loneliness: Confirmatory tests on survey data. Research on Aging, 28(5), 582-598. doi:10.1177/0164027506289723

Jong-Gierveld, J., \& Van Tilburg, T. (2010). The De Jong Gierveld short scales for emotional and social loneliness: Tested on data from 7 countries in the UN generations and gender surveys. European Journal of Ageing, 7(2), 121-130. doi:10.1007/s10433-010-0144-6

Leung, G. T. Y., Jong Gierveld, J., \& Lam, L. C. W. (2008). Validation of the Chinese translation of the 6-item De Jong Gierveld Loneliness Scale in elderly Chinese. International Psychogeriatrics, 20(6), 1262-1272. doi:10.1017/S1041610208007552

Luo, Y., Hawkley, L. C., Waite, L. J., \& Cacioppo, J. T. (2012). Loneliness, health, and mortality in old age: A national longitudinal study. Social Science \& Medicine, 74(6), 907-914. doi:10.1016/j.socscimed.2011.11.028

Maio, G. R., \& Esses, V. M. (2001). The need for affect: Individual differences in the motivation to approach or avoid emotions. Journal of Personality, 69(4), 583-615. doi:10.1111/1467-6494.694156 
Milfont, T. L., \& Fischer, R. (2010). Testing measurement invariance across groups: Applications in cross-cultural research. International Journal of Psychological Research, 3(1), 111-121. Retrieved from https://dialnet. unirioja.es/descarga/articulo/3296462.pdf

Peplau, L. A., \& Perlman, D. (1982). Loneliness: A sourcebook of current theory, research, and therapy. New York, NY: Wiley.

Pinquart, M., \& Sorensen, S. (2001). Influences on loneliness in older adults: A meta-analysis. Basic and Applied Social Psychology, 23(4), 245-266. doi:10.1207/ S15324834BASP2304_2

R Development Core Team. (2015). R: A language and environment for statistical computing. Retrieved from https://cran.r-project.org/doc/manuals/fullrefman.pdf

Raiche, G., Walls, T. A., Magis, D., Riopel, M., \& Blais, J.-G. (2013). Non-graphical solutions for Cattell's scree test. Methodology: European Journal of Research Methods for the Behavioral and Social Sciences, 9(1), 23-29. doi:10.1027/1614-2241/a000051

Rammstedt, B., \& John, O. P. (2007). Measuring personality in one minute or less: A 10-item short version of the Big Five Inventory in English and German. Journal of Research in Personality, 41(1), 203-212. doi:10.1016/j. jrp.2006.02.001

Revelle, W. (2013). Psych: Procedures for personality and psychological research. Retrieved from https:// personality-project.org/r/psych.manual.pdf

Rhemtulla, M., Brosseau-Liard, P. E., \& Savalei, V. (2012). When can categorical variables be treated as continuous? A comparison of robust continuous and categorical SEM estimation methods under suboptimal conditions. Psychological Methods, 17(3), 354-373. doi:10.1037/ a0029315

Rizopoulos, D. (2015). Package ltm: Latent Trait Models under IRT. Retrieved from https://cran.r-project.org/web/ packages/ltm/ltm.pdf

Samejima, F. (1968). Estimation of latent ability using a response pattern of graded scores. ETS Research Report, 1968(1), i-169. doi:10.1002/j.2333-8504.1968. tb00153.x

Schäfer, J., Opgen-Rhein, R., Zuber, V., Ahdesmäki, M., Silva, A. P. D., \& Strimmer, K. (2013). Corpcor: Efficient estimation of covariance and (partial) correlation. Retrieved from http://cran.rproject.org/web/packages/ corpcor/corpcor.pdf

Souza, R. V. L., Araújo, R. C. R., Gouveia, R. S. V., Coelho, G. L. H., \& Gouveia, V. V. (2014). The positivity dimension of well-being: Adaptation and psychometric evidence of a measure. Paidéia (Ribeirão Preto), 24(59), 305-312. doi:10.1590/1982-43272459201404
Steptoe, A., Shankar, A., Demakakos, P., \& Wardle, J. (2013). Social isolation, loneliness, and all-cause mortality in older men and women. Proceedings of the National Academy of Sciences of the United States of America, 110(15), 5797-5801. doi:10.1073/pnas.1219686110

Stickley, A., Koyanagi, A., Koposov, R., Schwab-Stone, M., \& Ruchkin, V. (2014). Loneliness and health risk behaviours among Russian and U.S. adolescents: A cross-sectional study. BMC Public Health, 14, 366. doi:10.1186/1471-2458-14-366

Tabachnick, B. G., \& Fidell, L. S. (2013). Using multivariate statistics (6th ed.). Boston, MA: Pearson.

Weiss, R. S. (1973). Loneliness: The experience of emotional and social isolation. Vol. 22. Cambridge, MA: The MIT Press.Gabriel Lins de Holanda Coelho is a Ph.D. candidate in Psychology at Cardiff University, United Kingdom.

Gabriel Lins de Holanda Coelho is a Ph.D. candidate in Psychology at Cardiff University, United Kingdom.

Patrícia Nunes da Fonseca is a Ph.D. in Social Psychology, and Professor of the Centro de Educação, at Universidade Federal da Paraíba, Brazil.

Valdiney Veloso Gouveia is a Ph.D. in Social Psychology, and Full Professor of the Centro de Ciências Humanas, Letras e Artes, at Universidade Federal da Paraíba, Brazil.

Lukas Jarmo Wolf is a Ph.D. in Psychology, and Research Associate at University of Bath, United Kingdom.

Roosevelt Vilar is a Ph.D. candidate in Psychology at Massey University, New Zealand.

Received: Dec. 11, 2015

1st Revision: May 12, 2016

Approved: Jul. 01, 2016

How to cite this article:

Coelho, G. L. H., Fonseca, P. N., Gouveia, V. V., Wolf, L. J., \& Vilar, R. (2018). De Jong Gierveld loneliness scale (short version): Validation for the Brazilian context. Paidéia (Ribeirão Preto), 28, e2805. doi: http://dx.doi.org/10.1590/1982-4327e2805 